\title{
Social Values and Ethics for Communicating the Corporate Identity
}

\author{
Cecilia Casalegno, Chiara Civera \\ University of Turin, Turin, Italy \\ Michela Pellicelli \\ University of Pavia, Pavia, Italy
}

\begin{abstract}
The on-going changes — as both opportunities and threats—push companies to look for competitive advantages and differentiation from competitors by making the best use of certain strategic levers; they are mainly represented by intangible resources (as harder to imitate) such as trade marks, brands, intellectual properties, ethics, and social values. Values in particular become more relevant if taking into consideration the company as a set of "human beings"; companies must be more integrated with its reference society and need to communicate with both external and internal audience covering different expectations, needs and cultures. In this sense, the traditional communication may be now defined as "integrated communication”. Accordingly, ethical principles and corporate social responsibility values are fundamental drivers of this integrated communication policies and are more and more reflected into the company's mission. The aim of the present paper is to analyze — at both a quality and an empirical level-the effectiveness of ethics and corporate social responsibility values as drivers for integrated communication. A sample of Italian listed food and beverage companies has been considered to establish if and how ethical principles and sharing corporate values have been built and implemented during the last years; the expected results are to demonstrate the link between literature and empirical evidence concerning effectiveness of integrated communication and its impact on company's financial results and-in particular—on value creation for shareholders. Eventually, the study results show that there might be huge benefits in using an integrated communication; talking to people in a coherent way and sharing values constantly make firms achieve best results.
\end{abstract}

Keywords: integrated communication, corporate social responsibility, brand, corporate values

\section{Introduction}

To be effective in achieving corporate goals, firms' strategy needs to be built not only with profit and market share objectives, but also with principles and values. What is called Organizational Culture (Schein, 2010)

Cecilia Casalegno, Researcher, Ph.D. in Business Administration, Faculty of Economics, University of Turin.

Chiara Civera, Ph.D. student in Business and Management, Faculty of Economics, University of Turin.

Michela Pellicelli, Researcher, Ph.D. in Business Administration, Faculty of Economics, University of Pavia.

Correspondence concerning this article should be addressed to Michela Pellicelli, Department of Economics and Business Sciences, Faculty of Economics, University of Pavia, Via San Felice 5, 27100 Pavia, Italy. E-mail: michela.pellicelli@eco.unipv.it. 
referred to the values and patterns of belief and behavior that are accepted and practiced by the members of a particular organization (Pringle, Jannings, \& Longeneckr, 1988).

When values coming from the corporate culture are strong and widely shared in every action and represent the integrated communication fundamental driver (Collesei \& Ravà, 2009; G. Belch, M. Belch, Kerr, \& Powell, 2009), the company often benefits.

Indeed, when considering the internal communication, many studies have shown that concerning to their peers, for example, firms with the strongest corporate cultures often experience higher stock prices, income growth and return on investment. Basically, shared values improve the alignment between employees' behaviour and corporate objectives (Casalegno, 2008).

The firm also needs to maintain effective and constant communication with the Investor Community in order to support the stock quotations with the most appropriate information. To this end it is necessary to provide financial as well as non-financial information and it can be external, with the objective to inform all the stakeholders, or internal, in order to communicate the corporate values and value based on management principles at every organizational level.

To show the link between financial results, the companies' integration with the environment and the sustainability of the business, Italian listed food and beverage companies that have been investigated. In particular, they are the following: (1) Parmalat; (2) Davide Campari Milano; (3) La Doria; (4) Centrale del Latte di Torino; and (5) Valsoia ${ }^{1}$.

The main purpose of the researches is to establish in which conditions firms' ethical principles and sharing corporate values can increase results if shared with all the stakeholders.

It has to be underlined that in this sector in particular the corporate communication is one of the most useful tools to increase customers' loyalty; in order to increase the sales firms need to assure customers that their products are healthy, their production respects the quality standards and the social and environmental responsibility rules.

The first part of the study aims to present how the Integrated Marketing Communication (IMC) can be considered as a very key way to develop a coherent message for different levels of firm' s interlocutors.

The second one shows the link between the corporate social responsibility—as one of the IMC strategic tools and the financial results.

The final part of the research is focused on the chosen firm's analysis in order to understand the correlation between firms' reputation, their behaviours, what they are telling public and their financial results.

\section{Integrated Marketing Communication (IMC) as a Vehicle to Empower Firm's Intangible Assets}

The principle concerning the fact that the most strategic and better controlled area in every firm is represented by its assets is undisputed (Pellicelli, 2010). This is more true in crisis periods in which customers can lose their brand loyalty to spend less and save money.

\footnotetext{
${ }^{1}$ Data from Aida Database for the year of 2010, order by revenues.
} 
Above all, it is about intangible assets as brands, patent, human resources, firm's values, internal behaviors; these are resources not reproducible by competitors and can represent the real key factors for a long-term competition capability.

At the beginning of the 21th century, organizations have learned the importance of corporate culture as cross-county set of values, beliefs, and relationships between individuals and functions that guide the decisions of the company in order to achieve its objectives. That is the collar can keep every part of a firm merged when there are problems concerning the international policy, the capacity to achieve the Group's goals in crisis time, the results which are difficult to obtain.

Indeed, corporate culture is a company's shared value and behaviors (Downey, 1987) and its main elements are going to be defined. It is not possible to talk about a group of standardize elements; it is necessary to talk about what every firm wants to express in its own mission and how it aims to achieve its goals.

Moreover, in this economic era, culture really represents economic value, because it is the basis to develop and nurture the intellectual capital growth of the corporation (Daum, 2003); How to do that? By improving the degree of communication, which has to be coherent and integrated at every level.

The environment as "symbolic field" (Martinelli, 1996) for sure is able to communicate more about economic and financial data; it communicates values, behavioral rules, shared meanings which let the organization define shared symbols which make dialog and interaction easer. At this stage, it can be highlighted two different levels of results - the internal and the external ones. The attention is focused on the first one: in this case communication tools enforce the collective identity and the corporate identity.

Concerning the internal communication contributes, firm workers have a huge culture degree in our times (Collesei \& Ravà, 2008) and they need to feel themselves as a great part of the whole organization to be effective and to achieve corporate goals.

According to Weil (1991), what internal communication contributes to firm value increase are the following:

- delivering the firm image as an unique and uniform draft;

- developing, at the same time, the individual and his/her potential in the community in which he/she is working;

- developing a collective imagination;

- creating a common slang;

- defining a corporate theme;

- making the corporate culture stronger and embedded in every action inside the firm;

- making the change.

Finally culture counts, when corporate values are strong and widely shared across the workforce, the company often benefits (Mcfarlin, 2002).

However, the issue has to be treated carefully because the positive impact of a strong corporate culture may be most pronounced when the environment in an industry is relatively stable, but what if firms are in recession or in a world of crisis?

The American Management Association and the Institute for Corporate Productivity released recently (Laff, 
2009) a report to understand the real power of the term corporate culture inside firms. The survey conducted reveals that employees are minimally aware of corporate culture elements; a majority of organizations surveyed say that their culture has been in place for several years, a lower percentage says that employees are familiar to a high extent with elements as compensation systems (35 percent), expectations about communication style (30 percent) and business strategy (27 percent). So the belief is that to make employees involved in the corporation values and life, senior managers have to be clearer in explaining firms' strategies and more inclined to communicate with their staff members.

On the other side, also employees have to pay attention to strategy, regardless how often it is communicated. Of course it is difficult to achieve this item, above all in an era of confusion due to the multiple functions that now exist inside a single organization.

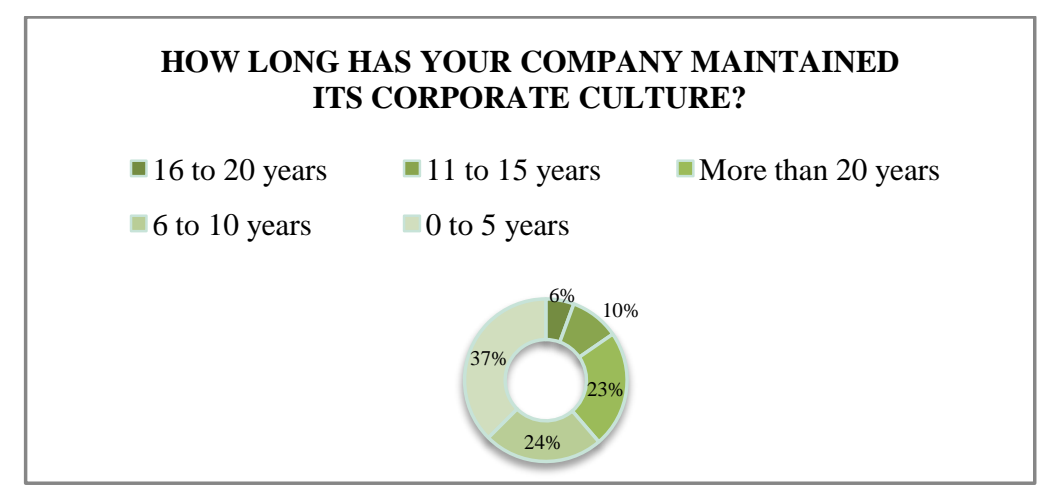

Figure 1. Firms and corporate culture. Source: Adapted from Laff (2009).

Figure 1 shows for how long companies have maintained their current culture.

Literature review shows that corporate culture elements are effective tools for the strategic and the operative management of every corporation.

However, the company board commitment is fundamental, so that every employee-despite his/her position — can trust in those values embedded in the firm structure even when nothing seems to give certainty.

Moreover, when talking about firms with business units located in different places, for them the corporate culture management is not so easy and this is the same for the managerial performances indicators.

Difficulties grow up from the fact that the way to manage and evaluate management performances affects not only value creation and company results, but also employees' motivation; difficulties are in making those strategic decisions which sometime can result in incongruent with corporate goals (O'Clock \& Devine, 2003).

When analyzing large firms, the cultural factor needs to be considered above all; ever most frequently it is possible to verify strong cultural differences and for that the management has often to face very serious comprehension difficulties.

Strategies adopted by a single strategic business unit must keep into account cultural differences of the human resources who — at every level—works inside the same corporation. In the meanwhile, they have to be coordinated and adapted to what the corporate wants to achieve.

Strategic goals directions are embedded in the firms' mission and communicating those values is a very used lever; values must lead human capital actions to strategic corporate goals. 
Strategic goals, mission, and the definition of every competitive strategy must be linked together and they have to be at the same level. The accomplishment of common goals, through a common code of conduct—which has to be on the same line of values firm brand wants to communicate to final clients—-must be not only known, but also experienced every day inside every strategic business unit of a same corporation.

Cultural factor represents an important element for every large firm and it can-if managed a right way-begin a true strategic lever.

According to Bennis and O’Toole (2009) until recently the way to evaluate international corporate (that has come from United States above all) was "the extent to which they creates wealth for investors". Today the competitive arena is more complicated in any industry sector and firm boards and leaders have to rebuild trust in institutions by honest and simple communication. The idea is that none organization can be honest with the public until it is not honest with people inside; it is possible to affirm that once strong inside, firms' values can easily pass to the outside and that means to customers first and this can make them buy the product - then to intermediaries, suppliers, and competitors.

Moreover, when questioning on what can be a very effective driver for buying behaviors processes, it is clear what values are. Responsibility and ethics are driving customers' expectations while the product is "naked" in front of the customer, so its quality cannot be enough as a long-term competitive source (Pitteri, 2002).

People in general are more focused on pollution and environment problems and now they embrace the ethic business both as customers and employees; corporate social responsibility can be considered as the new profit driver for companies and CEOs know that they must be mouth piece not only for company values but also of what concerns about corporate social responsibility and company goals.

How what said above can help firms to sell more and better? Today selling is more difficult, so the advertising and the promotion, the brand building and its language invention are getting more important (Lombardi, 2011); customers are not more passive and messages recipients, but also they interact with companies and are part of the brand experience process.

The first way to talk to people outside firms is the brand which is defined by David Aaker as a name or a distinctive symbol (for example a logo, a trademark, the packaging or design) that is useful to identify products or services sold by a seller or a group of sellers in order to differentiate them by other competitors (Aaker, 1997).

The meaning of a brand is to constantly satisfy the consumers' expectations or precede them, to point out the environmental factors by which these expectations are determined, to offer the right product or service (Minestroni, 2003).

According to this, the brand imposes itself as the first element communicating values outside the firm and adding value to company's products or services; the brand is built to satisfy consumers' needs in terms of both emotional and functional benefits.

\section{The Corporate Communication Impact on Shareholder Value Creation}

Following the acceptance of the principle that management needs to strive for the production of shareholder value, it much has been written about the advantages and operating policies in order to obtain shareholder value (Rappaport, 1986; Hennel \& Warner, 1998; Cornelius \& Davies, 1997). "Shareholder value is therefore defined 
as the difference between corporate value and debt, where corporate value is the sum of the future (or free) cash flows discounted at the WACC” (Black, Wright, \& Davies, 2001). "To maximize shareholder wealth, management must generate, evaluate, and select business strategies that will increase the corporate value” (Morin \& Jarrel, 2001). "Strictly speaking, firms are considered as systems for the creation of economic and financial value for their shareholders, and their performance-profit and the value of capital—is measured by a coherent system of monetary values” (Mella \& Gazzola, 2004).

Moreover, shareholder value creation in the short period can be also influenced by the corporate communication that can regard two macro areas: financial and social communication.

The firm must maintain effective and constant communication with the Investor Community in order to support the stock quotations with the most appropriate information. To this end, it is necessary to provide financial as well as non-financial information. If the objective is the creation of shareholder value, it is necessary to know what it means to create value for investors and which information will influence the share price. This will enable strategies to be adopted that are in line with shareholder expectations and will make communication more effective.

The financial communication is basically referred to balance sheet, reports, conferences, meetings, newsletters, press release and the objective is to inform the shareholders and the other stakeholders about the corporate financial and economic results also about eventual extraordinary facts or operations, as mergers and acquisitions that can increase the corporate value. Specifically there are various measurement methods used to communicate value to investors. At the corporate level, the measures normally used can be both internal (accounting data) and external (stock market data). Accounting measures, such as EPS, ROI, ROE and ROCE have the advantage that they are simple and easy to calculate. However, they refer to the short-term, while the creation of value depends on long-term cash flows. On the other hand, measures that are based on stock market evaluations, such as MVA, MBR, and TSR, present problems involving stock price fluctuations, which can depend on factors outside the control of management as well as that management, can act on (specific information, for example, acquisitions or mergers).

In order to complete the value communication process the management also develops the internal communication. It must be different for the various organizational levels: (1) The top management decides the key performance measures and the businesses control rules; (2) The senior management must translate the value objective in actions; and (3) The operational management programs the communication process finalized to the value principle diffusion inside the organization at every level.

In middle and large-sized companies the notion of the production of economic and financial value for shareholders must be broadened to also take in to account the social shared "value” (Harrison \& Carron, 1998), in the broader sense that the economic existence of a capitalistic firm must be appreciated, in terms of the sustainability of the development path of the firm, and evaluated by a wide range of social performance measures of outcome or benefit: the efficiency of materials, technical innovation, energy efficiency, community relations, eco design, product recyclability and employee relations ${ }^{2}$.

\footnotetext{
2 The concept of sustainability was originally introduced in the 1987 Brundtland report, Our Common Future, which was commissioned for the United Nations. The central principle of this definition is "development which meets the needs of the present without compromising the ability of future generations to meet their own needs"” (WCED, 1987).
} 
This implies, on the one hand, the organizational ability to recognize the set of relevant stakeholders as well as to identify their expectations, and on the other hand the capability to communicate the global "value" produced in terms of social benefits and prevented damage to the physical environment.

All of these information are fundamental in evaluating the relationship between the firm and the macrosystem; however, it cannot be included in the corporate balance as understood in an accounting sense: as the representation of the system of values produced by the firm.

For this reason, the traditional corporate balance cannot account for the ethical values and other intangibles which are fundamental to the success of the enterprise in creating economic values.

Corporate social responsibility policies may impact on differentiation, in terms of improved brand reputation, access to new markets and niches, improved perception of how well company is managed, improved ability to attract and retain top talent, enhanced stakeholders/investors relations (Haanaes et al., 2011), better workplaces which can be more conducive to better innovation of products/services and business models and processes as well (European Commission, 2008), improved competitive positioning, customer loyalty (European Commission, 2007).

Corporate social responsibility takes actions beyond the environmental and economic/business and aims at implementing legal obligations in the triple bottom line approach, in which the economic, the social and the environmental perspectives are all relevant.

Moreover many researches demonstrate the positive relation between environmental performance and financial performance (Kenneth, Archie, \& Hatfield, 1985). Also Fombrun and Shanley (1990) established that investing in CSR attributes and activities may be important elements of product differentiation and reputation building. As Dahlsrud (2008) underlined

Due to globalization, the context in which business operates is changing at an increasingly rapid pace. New stakeholders and different national legislations are putting new expectations on business and altering how the social, environmental and economic impacts should be optimally balanced in decision making. Thus, in such a context, CSR management tools are needed, in addition to the previously established patterns, to develop and implement a successful business strategy. (p. 6)

\section{Research Design}

\section{The Italian Listed Food and Beverage Companies}

The study considers the Italian listed food and beverage companies (last available fiscal years) and the research purpose is to analyze the link between the integrated communication and the financial results, so firstly it has been considered how and what they communicate to their stakeholders and how they are involved in the sustainability values; secondly their financial results and the value creation for shareholder have been analyzed.

As shown in the previous paragraph, these firms pay a lot of attention on social values and ethics for communicating their corporate identity. At the same time, from the evidence they have good financial performances and a consistent shareholder value creation during the turbulent periods.

It can also be underlined that 2010 was a year of recovery from the serious economic and financial crises of 2008 and 2009. The firms considered: (1) Parmalat; (2) Davide Campari Milano; (3) La Doria; (4) Centrale del Latte di Torino; and (5) Valsoia. Which seem to have emerged from the crisis, although the recovery is based 
essentially on the growth of production and exports, while the internal market remains disappointing.

Moreover, the food and beverage sector appears to be the more solid during the heavy financial market crisis of the summer 2011 and Davide Campari Milano is the firm within the sector that has achieved the best results.

The sector is commonly defined as an anti-cycle sector and the more resistant to the 2011 crisis. Investors buy food and beverage shares in order to protect their capitals. In particular, the share performance of Campari exceeds the others with very good performances for all the year of 2010 and also in August 2011 during the serious fall of the European and USA Stock Exchange.

The Italian listed companies have been investigated in order to define the group structure and mission, the role of "integrated communication" and its impact on shareholder value creation:

(1) Parmalat is a multinationaldairy and food corporation. Despite the company collapsed in 2003 with a €14 billion hole in its accounts and it was remembered as the biggest bankruptcy in Europe, the Group was saved by the Italian Government. The extraordinary administration and the recovery plan have permitted the Group to develop its global presence in this way: Canada (37\% of the 2010 revenues), Italy (22\%) and other Europe (4\%), Australia (17\%), South Africa (10\%), Central and South America (10\%). The production is based especially on the following product divisions: milk (59.2\% of the 2010 revenues), milk derivative as yoghurt, dessert, cheese (32.3\%) and fruit base drink (6\%) ${ }^{3}$. From July 2011, Parmalat is a subsidiary of French group Lactalis.

The strategy pursued by the group is based on the identification of a clear mission in the global market and the intent is to consolidate the position as a primary player both domestically and internationally. The mission of the Parmalat Group (Parmalat Annual Report, 2011) is as follows:

The Parmalat Group is an Italian food-industry group with a multilocal strategy that seeks to increase the well-being of consumers throughout the world. The ultimate purpose of the Group is to create value for its shareholders while adhering to ethical principles of business conduct, to perform a useful social function by fostering the professional development of its employees and associates, and to serve the communities in which it operates by contributing to their economic and social progress. We intend to establish Parmalat as one of the top players in the global market, which delivers improved nutrition and wellness to consumers, and attains clear leadership in selected product categories and countries with high growth potential for the Group. Milk and dairy products and fruit beverages, foods that play an essential role in everyone's daily diet, are key categories for the Group. (p. 2)

The company's goal is the maximization of the shareholder value and the social and ethical principles are considered the necessary tools in order to guarantee the sustainability in the long period, as underlined in the Parmalat Code of Ethics, 2010:

The Group's aim is to maximize shareholder value by striving to compensate risk taking adequately and thus increase the Company's financial strength in a manner that is sustainable over the intermediate term, in accordance with market rules and the principles of fairness and transparency. Parmalat protects and recognizes the overriding interest of the Company and of the collective interest of those who hold investments in its equity capital (shareholders) over the specific interests of individual shareholders or groups of shareholders. (p. 8)

(2) Davide Campari Milano is the holding of Campari Group, the beverage multinational mainly operates in the Americas (34.8\% of 2010 sales), in Italy (34.2\%) and the rest of Europe (23.8\%) and it is specialized in spirits

\footnotetext{
3 Data available in the Parmalat Annual Report, 2010.
} 
(75.4\%), wines (15\%) and soft drinks (8.5\%) ${ }^{4}$.

The company pays a lot of attention to communicate its results with investors, analysts and financial markets around the world with a view to providing complete, accurate and timely information on its operations. Numerous meetings with institutional investors are organised at the main stock exchanges in Europe, the US and Canada.

(3) La Doria Group is an Italian leading manufacturer of canned food (tomato-based products, fruit juices/beverages and canned vegetables) and it is controlled by Ferrarioli Family.

In 2010, the Company expanded its overseas presence, increased at the same time its share in the Italian market and continued to invest in innovation and segmentation for private label products. La Doria operates in the global market: North Europe (64.0\% of 2010 sales), Italy (21.4\%), other European Countries (4.4\%), Australia/New Zealand (4.5\%), Asia (4.1\%) and the main products are divided in four lines: red line (31.2\%), fruit line (19.1\%), vegetable line (24.8\%), and others $(25 \%)^{5}$.

The mission and the strategic objectives of the Doria Group are the following: to maintain further growth in the European tomato and vegetable private label market, to consolidate the leadership in the Italian market for private labels fruit juices, to become a major player in the Italian market also in tomato and vegetable-based products under private labels.

The Company's mission will remain strongly focused on its core business, production of private labels processed vegetable foods with the following objectives: To maintain an EBITDA MARGIN LEVEL >= 9, Reduction in net debt establishing more solid balance sheet ratios with a 2013 Debt/Editda ratio = 2. (La Doria Company Presentation, 2011, p. 22)

(4) Centrale del Latte di Torino Group is an inter-regional in scope, and it is focused on the production and direct sale of dairy products such as fresh milk, long-life (UHT) milk, yogurt, and fresh vegetables. Moreover for some years the Group has been selling own-brand packaged products in the fresh food sector, such as eggs, cheeses, pasta, vegetables and fresh salads, produced either directly or through carefully selected third-party companies.

Their mission is

Producing and marketing high quality products in thefollowing segments: fresh milk, long life (UHT) and ESL (Extended shelf life), ready-to-eat (salad), yogur, fresh, ESL and UHT cream.Developing and strengthening our role of interregionalnetwork among large groups and small-sized local players. (Centrale del Latte di Torino Company Presentation, 2011, p. 5)

(5) Valsoia is an Italian health food, functional foods and functional drinks company. It provides drinks, desserts, ice creams, soya yoghurts, biscuits, veggie burgers, and cutlets, as well as savouries, snacks, rice-based drinks, savoury rice cakes, soya drinks, and yoghurt ice creams. It also distributes breakfast cereals. Valsoia markets its products under the Valsoia, Rys, Naturattiva, and Yogurtal brand names in Austria, Germany, Greece, Slovenia, Spain, and Switzerland.

\footnotetext{
${ }^{4}$ Data available in the Davide Campari Milano Annual Report, 2010.

${ }^{5}$ Data available in the La Doria Annual Report, 2010.
} 


\section{IMC Attitude Among the Companies of the Sample}

As said above, in order to build a strong relationship with customers, nowadays it is necessary to give them a reason which goes beyond the product/service proposed. The "unique selling proposition" (USP) is to create a huge difference compared to the market; accordingly, the history, the values, the vision of a firm have to be studied and compared to competitors are used to communicating of themselves (Collesei \& Ravà, 2008). This analysis takes into account the social and economic indicators needed to be crossed to the firm's strengths. This is a very rational moment and allows managers to understand firm's basis, in order to answer the following question "Why people outside are choosing me instead of my competitors?” (Collesei \& Ravà, 2008).

Everything is inside the firm itself and a coherent communication can make the firm closer to the target market.

As told before, firms need to communicate and integrate the different levels of their communication; over competition, rapid technology development and more aware customers make firms search for values to communicate which should be stable and lasting (Collesei \& Ravà, 2008).

The sample taken into consideration shows that a coherent communication of values and a total integration with the environment can make firms achieve the best results; the sector analyzed—food and beverage—is the best and leading sector in terms of financial results in the third quarter of the year of 2011.

Before putting communication behaviors of our sample in evidence, it is useful to understand what are the most important guidelines of this sector in particular.

In the food and beverage sector, firms can exploit a new opportunity: offering their products as medicines.

The major attention for the health prevention has made people consider food as the best way to prevent diseases; one of the conerstones of the prevention is represented by life behaviors of which eating is one of the most important elements.

Moreover, firms in this sector do not have the traditional features of healthiness and sustainability—or do not know how to communicate them in the right, modern and effective way-and sometimes they risk to fail and to become a non-desirable, healthy, and fashionable goods producer.

Essential values for a successful communication in the food and beverage market are the following: good (which means tradition and reassurance), healthy (with a solid scientific base), and sustainable (means ethics and educational).

Those elements are important if compared to the customer features; it has already reported about the evolution of customers and their capability to understand better than in the past what they really need. This is true to a certain extent, because what customers really need is to be reassured by products they buy; they need certainties which can be found in firms' values and promises; this is more true if compared to the period we are living in. Crisis makes customers more uncertain; they need to find something of reassuring in the present and for the future. Food and beverage sector is the best to play this role.

Once again brand and social values communication are fundamental to make firms integrated to the environment, on the one hand, and stakeholders satisfied and trustful, on the other hand.

Talking about the sample none of the analyzed firms publishes their own sustainability report, while everyone is focused on brand communication and sustainability and, most improtantly, they communicate their 
integration with the environment.

Eventually, there is a huge use of integrated communication within them because the majority of communication tools are available on firms' web site. When a firm decides to talk through internet it never knows who is going to read web pages; this is the reason why every information, news, and value should be expressed with coherence and should be integrated to the other ones. Firms must reach stakeholders and must be clearly understood in the same way by everyone.

\section{Brand Communication and Shared Values Among the Sample}

Parmalat (the first firm of the sample in terms of revenues) produces dairy products like chocolate pudding, milk, enriched milk, yogurt and fruit juices and enriched fruit juices. The brand communication is implemented on the web site in which people can find the needed information about products properties and the continuous research to improve products and processes innovation. The main communicated goal is to achieve the higher degree of quality in order to satisfy customers' needs. Parmalat knows that today customers want the best for their body and mind balance and its research is focused on it.

Being ethic and social responsible represents a critical success factor for firms; if we take into consideration Parmalat and its mission, for example, the first goal is to be the best in research and development to deliver customers healthy products. Parmalat needs a high degree of technology to do that; for this reason a Research and Nutrition Centre has been founded.

Moreover, to allow stakeholders to know what are the improvements in terms of research, on the web site of Parmalat special pages presenting publications, sector events and instructive papers can be found.

Campari Group (the second in the ranking considering revenues) constituted by Davide Campari-Milano S.p.A. and its direct or indirect controlled companies, is a player within the spirits industry. The Group operates in over 190 countries and has leadership positions in the Italian and Brazilian markets; it is a key player in the US, Germany and other markets, with a wide portfolio divided into three main segments: spirits, wines, and soft drinks (Campari, Code of Ethics). There are no doubts that there are not healthy ingredients in spirit recipes, but the brand communicates more than just a product. For instance, Campari Group has got a written code of ethics; this code is easily available on the web site (http://www.camparigroup.com) and this helps to position the brand in the mind of customers. Campari Group products are more than spirits; they represent principles such as honesty, confidentially (every information and news concerning the Group is put on line for stakeholders) and transparency. Moreover, Campari Group is a member with other organizations for the promotion of responsible drinking programs and education; it condemns excessive and underage drinking and is concerned about its negative effects on daily lives (for example, drinking and driving, alcohol related illnesses, dangerous activities), which also cause a negative image and damage the respectability of the industry in general. Eventually, the Group brand strategy is focused on globalization and the main goal is to implement the wordwide presence by refreshing key brands constantly. They aim at innovating products constantly, developing the presence in emerging markets and paying attention to costs (Gruppo Campari, 2011).

La Doria Group (at the third place in the ranking) is an Italian leading manufacturer of canned food (tomato-based products, fruit juices/beverages, and canned vegetables) and its business model is oriented to the satisfaction of the "private label” customer's needs. The main goal in terms of production is to deliver the best 
quality at a competitive price. Brands are communicated and known for their quality and the high degree of innovation. Different brand strategies have been implemented (La Doria Company presentation 2011): the private label one (for players like Auchan, Conad, Carrefour, Lidl, Tesco), the industry one (for players like Unilever, Heinz, Zuegg) and the company one (with the brands La Doria, Vivi G, and La Romanella). Brand values are the same for every product line and stakeholders can collect information about them simply reading the web site.

Concerning strategic goals, becoming the leader in Italian market and achieving higher positions in foreign markets are the most important. This is possible due to the cost rationalization actions and a great attention to consumptions: reducing raw material costs, increasing energy efficiency-through the use of cheaper and renewable energy sources and reduced consumption.

Since 1950, Centrale del Latte (at the fourth place in the ranking) has been the leading brand of milk in Turin (Piedmont). During the years the Group experienced a huge growth in order to become a multiregional company active in the production and distribution of milk, milk derivatives, and other fresh products (Company presentation, 2011). During the years, Centrale del Latte has developed the concept of healthy food; on the web site it is possible to find a special page called "Health Guide" in which every reader can become aware of the supply chain of products, how probiotics and fresh food are good for human body, what are the certifications owned by Centrale del Latte and a detailed description of other products.

The main adopted strategy is the differentiation (they only sell premium price products). The goal is to maintain high-quality production, continuous innovation (first Italian company commercializing fresh milk in 1.5 lt packaging), strong diversification strategy (fresh and UHT milk, yogurt and desserts, cheese, ready-to-eat salads, eggs, fresh pasta, pesto sauce, cream) and effective distribution network. Moreover, the preservation of its “daily and dairy” relationship with its customers represents a strong value driving activities day by day. Talking about the communication, the web site is the most complete way Centrale del Latte has to inform people about its products and shared values which are easily found by reading the conduct code and internal dealing document.

The last analyzed company is Valsoia; this firm has been the Italian premier health food company since its foundation in 1990, leading the market for quality and product innovation (Retrieved from http://www.valsoia.it). This is the case in which product and values are strongly connected; Valsoia products are ethic and healthy, because they are made to be vitamin-rich, low fat, high protein, gluten-free, probiotic, and calcium-enriched options for the health-conscious, vegetarians and vegans, as well as people with food intolerances. This perfectly fits what said before concerning the new role of food; being the best way to cure people's body and mind. The integrated communication of Valsoia is based on this new role. The social mission and its homogeneity emerges by simply exploring the web site. This firm operates at every communication level promoting the same values because the brand is the principal vehicle of them. As told before, neither Valsoia publishes a responsibility report, but maybe it does not need one; principles are so clear at a first glance.

\section{Integration With the Environment}

One of the most important communication tools is represented by the integration with the environment; this is easily achievable by using below the line activities like events, out of home actions, internet interaction with stakeholders. 
Parmalat chooses to involve stakeholders (customers first) through summer events on the Italian beaches, school educational initiatives and the chance for web site readers of downloading the "Parmalat Magazine" from which more information about food healthy properties can be gathered.

Campari Group has developed a specific web site (http://www.campari.com) in order to talk to people-young above all—in which reader can enter only if on age ${ }^{6}$. Major information about brands history, cocktails, and limited editions are here available together as well as Campari Group special images; moreover people can find a "friendsquare" in which they can interact with other enrolled people.

La Doria, instead, provides on its web site the production process video tour and its top news concerning its recent history and initiatives.

Eventually, Centrale del Latte and Valsoia have created a special on line club in which visitors can enroll in order to know more about products, food properties, and special sector news.

\section{Key Findings and Conclusions}

Analyzing the financial and shareholder value creation of the Italian listed food and beverage companies, the following results can be highlighted:

(1) In the last years Parmalat has obtained very good results. For Parmalat, 2010 was a year during which industrial profitability improved, compared with 2009, confirming the soundness of the decision to pursue a strategy of greater focus on the group's strong brands, both globally and locally, and increased industrial profitability. As can be seen in the Figure 2 for the year of 2010 the total revenues increased from the previous year to reach $€ 4,301$ million;

(2) The performances achieved by Davide Campari Milano in 2010 was unquestionably good due to both the positive trend in consumption of the group's main products and the recent acquisitions of Carolans Irish Cream (2010), Frangelico (2010), Irish (2010), Wild Turkey (2009), American Honey (2009), which have been integrated very effectively and have given the expected results. In particular the group sales rose by $15.3 \%$ in 2010 against the revenues of the previous year of €1,163.0 million (see Figure 2).

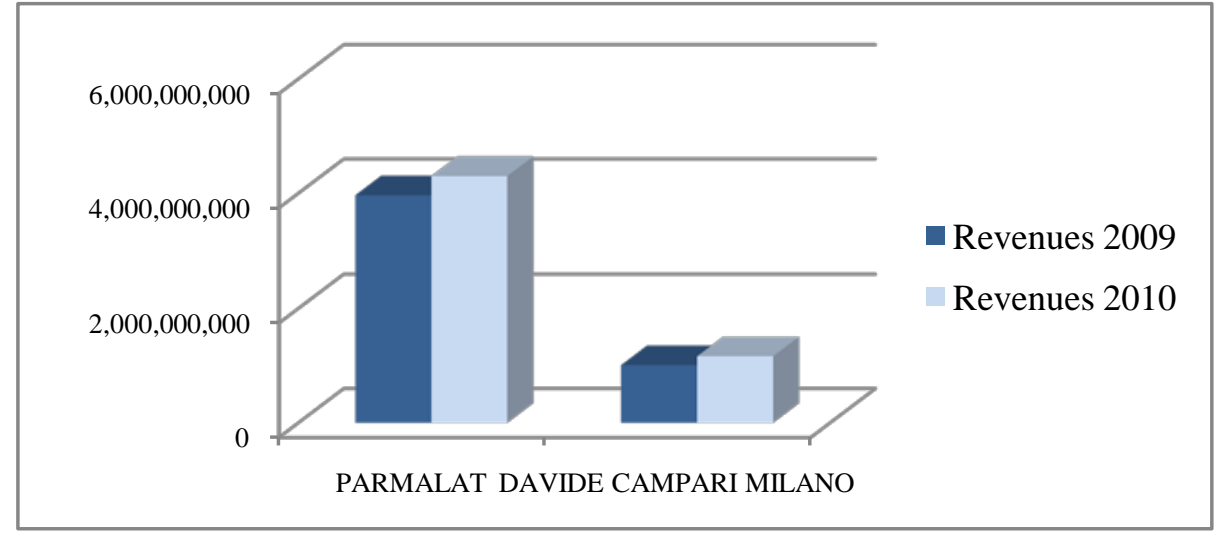

Figure 2. The revenues of Parmalat and Davide Campari Milano for the years of 2010 and 2009. Source: Data processed from Aida Database (2010).

\footnotetext{
${ }^{6}$ In order to access the web site it is necessary to insert the date of birth.
} 
Moreover, Campari has been achieving very good results in shareholder value creation for all the year of 2010, confirmed by the trend in the August 2011: the share price rose by 15\% when other shares lost until the $40 \%$, as in the case of the telecommunication and energy sector (Il Sole24Ore, 2011);

(3) La Doria Group achieved very good results as well—ahead of expectations in a difficult general and food production sector environment. The results in 2010 reflect the market context outlined above and the actions taken to improve efficiency and costs reduction. Consolidated revenues in 2010 amounted to $€ 443,5$ million, decreasing by only $0.53 \%$ if compared to the $€ 445,9$ million of the previous year. Sales volumes increased significantly, in particular of tomato-based products and canned vegetables. The results are also considered strong from a financial point of view with a significant further reduction of the net debt ${ }^{7}$;

(4) Centrale del Latte di Torino has reached good results in shareholder value creation for all the year of 2010 compared with the S\&P/MIB index as can be seen in the Figure 3 below;

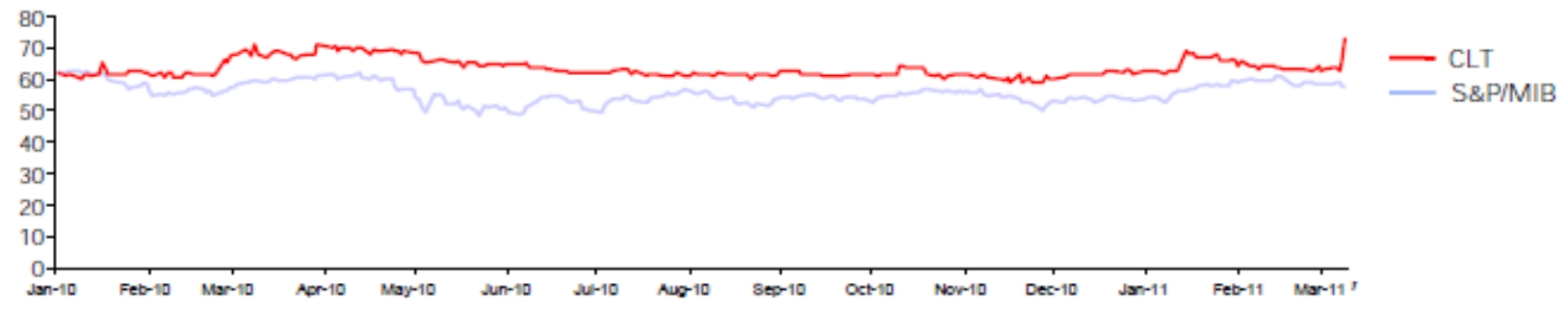

Figure 3. Centrale del Latte di Torino share price and S\&P/MIB index for the period from January 2010 to February 2011. Source: Elaborationfrom JCF and Bloomberg Data.

(5) As Figure 4 shows, also Valsoia sales show a rise of 7.2\% in 2010 to $€ 56.1$ million.

It can be definitively said that all the Italian listed food and beverage present a good market and financial position also considering the very difficult period for the Italian Stock Exchange.

Moreover, if taking into account the Return on Equity results (see Figure 5), it can underline a positive and excellent trend for Campari and Valsoia.

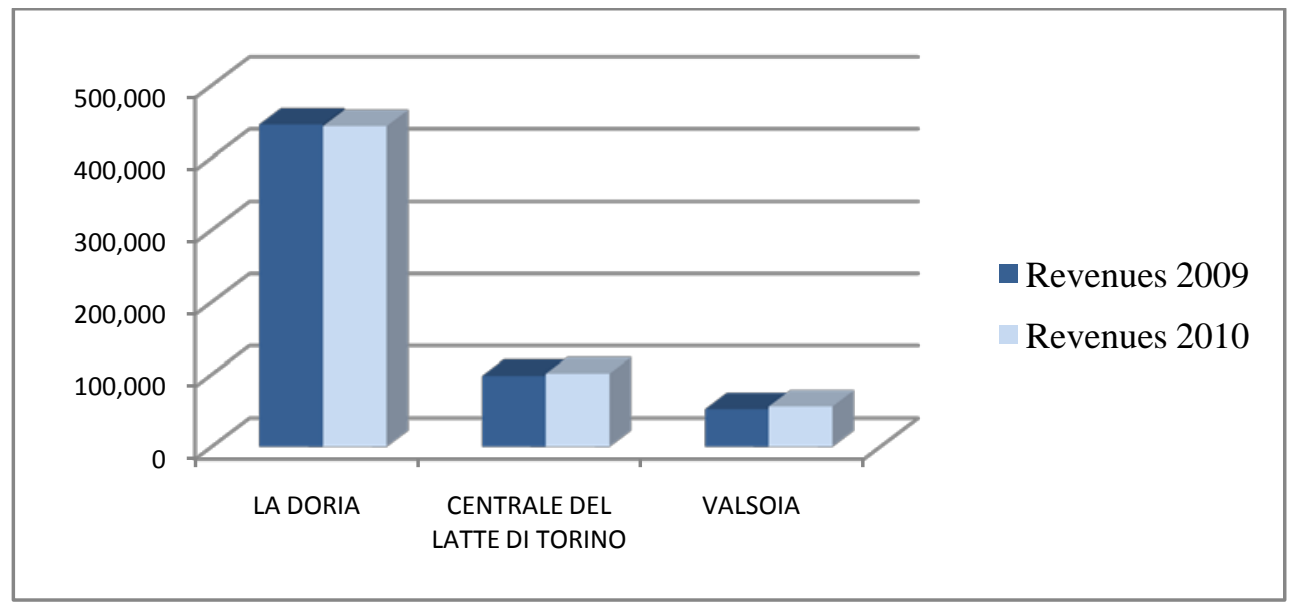

Figure 4. The revenues of La Doria, Centrale del Latte di Torino and Valsoia for the years of 2010 and 2009. Source: Data processed from Aida Database (2010).

\footnotetext{
${ }^{7}$ Data available in the La Doria Annual Report, 2010.
} 


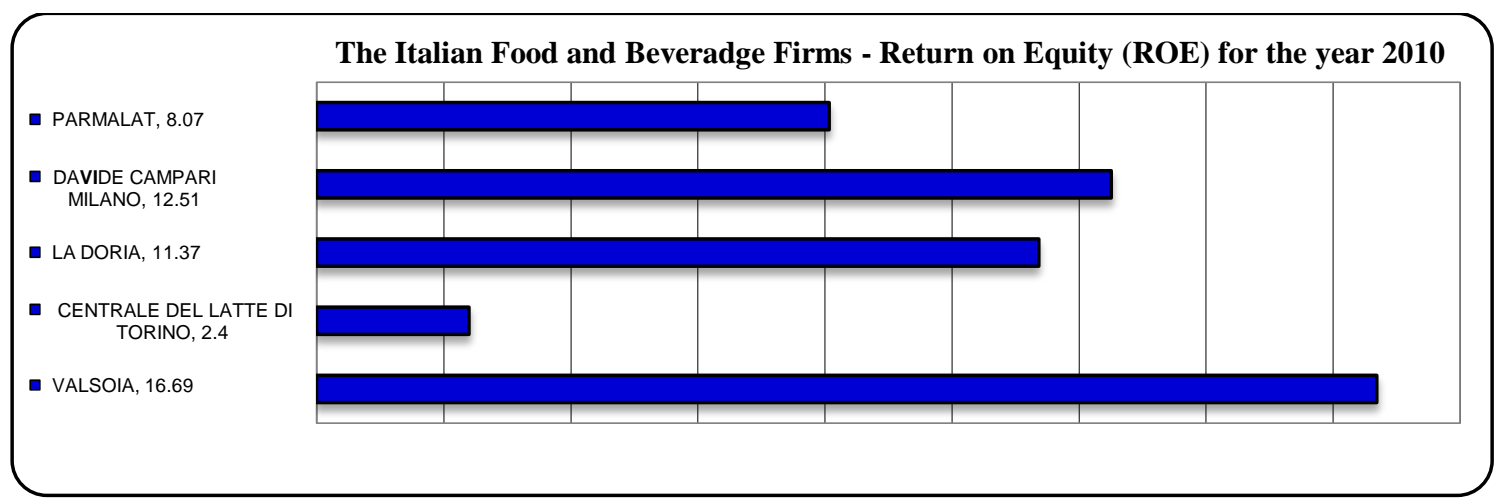

Figure 5. The Italian food and beverage return on Equity. Source: Data processed from Aida Database (2010).

Eventually, the study results show that there might be huge benefits in using an integrated communication; talking to people in a coherent way and sharing values constantly make firms achieve best results. This is particular in the food and beverage sector in which players need to coordinate all the communication levers and all the points of contact between themselves and the customers in order to build loyalty and retention. Accordingly, both Above The Line (ATL) and Below The Line (BTL) programs are useful and necessary as well as product innovation in order to positively affect stock market return and benefits for stakeholders.

\section{References}

Aaker, D. A. (1996). Building strong brands. New York: The Free Press.

Aaker, D. A. (1997). Brand equity. Franco Angeli.

Arthur, W. B. (1973). Optimal control theory with time delay. Berkeley: University of California Press.

Belch, G., Belch, M., Kerr, G., \& Powell, I. (2009). Advertising and promotion. McGraw Hill.

Bennis, W., \& O’Toole, J. (2009). A culture of candor. Harvard Business review, 87(6), 54-61.

Berson, Y., Oreg, S., \& Dvir, T. (2005). Organizational culture as a mediator of CEO values and organizational performance. Academy of Management Proceedings (pp. FF1-FF6).

Black, A., Wright, P., \& Davies, J. (2001). In search of shareholder value (2th ed.), Financial Time. London: Prentice Hall.

Campari Group. (2011). Report Overview \& recent developments. Retrieved from http://www.caparigroup.com

Casalegno, C. (2008). Leadership Development come Strumento Strategico di Gestione. Giappichelli, Torino, Italy.

Collesei, U., \& Ravà, V. (2008). La comunicazione d'azienda. Isedi, Torino, Italy.

Cornelius, I., \& Davies, M. (1991). Shareholder Value. Financial Times. London: Pearson Professional.

Dahlsrud, A. (2006). How corporate social responsibility is defined: An analysis of 37 definitions. Corporate Social Responsibility and Environmental Management, 15, 1-13.

Daum, J. H. (2003). Intangible assets and value creation. West Sussex, England: Wiley \& Sons.

Downey, S. M. (1986/1987). The relationship between corporate culture and corporate identity. Public Relations Quarterlv (pp. 7-12).

Drucker, P. F. (1980). Managing in turbolent times. New York: Harper \& Raw.

European Commission. (2007). Opportunity and responsibility: How to help more small business to integrate social and environmental issues into what they do. Brussels, Belgium.

European Commission. (2008). European competitiveness report. Brussels.

Fombrun, C., \& Shanley, M. (1990). What's in a name? Reputation building and corporate strategy. Academy of Management Journal, 33, 233-258.

Garvin, D. A., \& Roberto, M. A. (2005). Change through persuasion. Harvard Business Review, 83(2), 104-112.

Haanaes, K., Balagopal, B., Arthur, D., Kong, M., Velken, I., Hopkins, M., \& Kruschwitz, N. (2011). New sustainability study: The “embracers” seize advantage. Mit Sloan Review, 52(3), 23-35.

Hammer, M., \& Champy, J. (1993). Reeingeenering the corporation. New York: Harper Business. 
Harrison, J., \& Carron, H. (1998). Strategic management of organizations and stakeholders: Concepts and cases (2th ed.).

Hennel, A., \& Warner, A. (1998). Financial performance measurement and shareholder value explained. Financial Times Management. London, UK.

Kenneth, E. A., Archie, B. C., \& Hatfield, J. D. (1985, June). An empirical examination of the relationship between corporate social responsibility and profitability. Academy of Management, 28(2), 446-463.

Il Sole24Ore (2011). Campari, August 18th.

Laff, M. (2009). Culture cloud. T+D, 63(2), 16-17.

Lawer III, E. E., Pringle, A., Branham, F. L., Cornelius, J., \& Martin, J. (2008). Why are we losing all our good people? Harvard Business Review, 86(6), 41-51.

Lombardi, M. (2011). La strategia in pubblicità. Manuale di tecnica multimediale: dai media classici al digitale. Franco Angeli, Milano.

Martinelli, A. (1996). La comunicazione di impresa ed il sistema dei media. Sviluppo ed Organizzazione, 98.

Mella, P. (2005). Performance indicators in business value-creating organizations. Economia Aziendale 2000 Web (pp. 25-32). Retrieved from http://www.ea2000.it2/

Mella, P., \& Gazzola, P. (2004). From values to "value”: From the creation of the value of firms to sustainable growth. Rivista Economia Aziendale web (pp. 1-18). Retrieved from http://www.ea2000.it, 3/2004

Minestroni, L. (2003). L'alchimia della marca. Fenomenologia di un moltiplicatore di valore (Brand Alchemy. Phenomenology doctrine of a value multiplier). Franco Angeli, Milano, Italy.

Mintzberg, H., \& Van der Heyden, L. (1999). Organigraphs: Drawing how companies really work.Harvard Business Review, 77(5), 87-94.

Morin, R., \& Jarrel, S. (2001). Driving shareholder value. New York:McGraw-Hill.

O’Clock, P., \& Devine, K. (2003). The role of strategy and culture in the performances evaluation of international strategic business units.Management Accounting Quarterly, 4(2), 18-26.

Pellicelli, G. (2010). Strategie d'impresa.Egea, Milano, Italy.

Pitteri, D. (2002).La pubblicità in Italia. Dal dopoguerra ad oggi. Roma: GLF Editori.

Prince, E. T. (2006). The valuation approach to ROI.Chief Learning Officer, 5(11), 44-47.

Pringle, C. D., Jannings, D. F., \& Longeneckr, J. G. (1988). Managing organizations: Functions and behaviors. Columbus, O.H.: Merrill Publishing Company.

Rappaport, A. (1986). Creating shareholder value. New York: The Free Press.

Schein, E. (2010). Organizational culture and leadership. Saint Francisco: Wiley and Sons.

Weil, P. (1991). Communication Oblige. FrancoAngeli. Milano, Italy.

Wright, P., Kroll, M. J., \& Parnell, J. (1998). Strategic management. London: Prentice Hall. 